\title{
A REFORMA DO ENSINO MÉDIO: DESAFIOS À EDUCAÇÃO PROFISSIONAL
}

\author{
C. J. FERRETTI \\ Programa de Pós-Graduação História, Política, Sociedade da PUC-SP \\ celsojoaoferretti@gmail.com
}

Submetido 22/02/2018 - Aceito 06/05/2018

DOI: $10.15628 /$ holos.2018.6975

\section{RESUMO}

Neste texto pretende-se realizar a análise da Lei 13.415/2017, no que respeita especificamente aos artigos e parágrafos que dizem respeito à educação profissional técnica de nível médio. Considera-se que, apesar da Lei em pauta, além da Medida Provisória que Ihe deu origem, ter sido já objeto de ponderações que as abordam em vários de seus aspectos, faz-se necessária a presente análise, pois ela permite vislumbrar que concepções de educação profissional informam o documento legal e que tipo de trabalhador se pretende formar num contexto de flexibilização do trabalho e de cerceamento de direitos trabalhistas.

PALAVRAS-CHAVE: Lei 13.415/2017; reforma do ensino médio; educação profissional técnica de nível médio

\section{MIDDLE SCHOOL REFORM: CHALLENGES TO PROFESSIONAL EDUCATION}

\begin{abstract}
In this text we intend to carry out the analysis of Law 13.415 / 2017, specifically regarding the articles and paragraphs that concerns to the professional technical education at the secondary level. It is considered that, although the Law in question, in addition to the Provisional Measure that gave rise to it, has already
\end{abstract}

been the subject of ponderations that address them in several aspects, this analysis is necessary, since it allows us to glimpse which conceptions of professional education inform the legal document and what type of worker one intends to form in a context of labor flexibility and the restriction of labor rights.

KEYWORDS: Law 13.415/2017; High school reform; professional technical education at the secondary level. 


\section{APRESENTAÇÃO}

Embora a reforma do Ensino Médio, realizada pelo MEC em 2017 se refira a vários aspectos dessa etapa da educação básica, neste texto nos deteremos sobre uma particularidade da proposta - qual seja, a formação técnica e profissional - que, por suposto, é afetada pelo conjunto desta, assim como pelos objetivos que a conformaram. Tal formação constitui um dos cinco itinerários em que o currículo do Ensino Médio foi subdividido, segundo os parâmetros de flexibilização adotados por seus propositores.

$\mathrm{Na}$ abordagem desta questão é necessário considerar que, para além do exame do conteúdo da proposta, quanto à formação técnica e profissional, deve ser levado em conta o momento em que tal análise se realiza, ou seja, posteriormente à aprovação, pelo Congresso Nacional, da Lei 13.415. Isto significa ponderar, também, sobre a implementação da Lei, em nível nacional, o que implicará provavelmente, a produção de regulamentações, nesse nível, assim como no nível dos diferentes entes nacionais, com as particularidades e limites relativos aos sistemas estaduais de ensino, podendo, tais regulamentações, tornar mais explícitas as intenções presentes no documento legal.

Evidentemente não se tratará desse ponto no texto, a não ser sob a forma de hipóteses, dado que o processo de implementação da reforma curricular definida pela referida Lei nas escolas desses diferentes sistemas se dará, conforme o artigo 12엄 desta, de acordo com cronograma a ser estabelecido "no primeiro ano letivo subsequente à data de publicação da Base Nacional Comum Curricular, iniciando-se o processo de implementação (nosso grifo), conforme o referido cronograma, a partir do segundo ano letivo subsequente à homologação da Base Nacional Comum Curricular" que, no caso do Ensino Médio ainda está em fase de elaboração.

Ou seja, a efetivação da reforma curricular nas escolas do Ensino Médio deverá ocorrer apenas em 2019, mas será, certamente, precedida daquelas regulamentações antes referidas, assim como, provavelmente, no caso dos sistemas públicos de ensino, da preparação de materiais e da realização de processos de formação de professores, do "convencimento" destes, dos gestores e de jovens e seus familiares a respeito das benesses do novo currículo, além da definição das instituições e organizações parceiras, que também oferecerão educação profissional técnica de nível médio, subsidiadas com recursos públicos. Nesse sentido, o processo de implementação da reforma, em sentido amplo, e do currículo, em sentido estrito, configura-se como nova arena de disputa política, assim como espaço de pesquisa, em particular, para os membros da academia, assim como para professores e gestores que se envolveram na crítica à forma e ao conteúdo da MP 746, hoje Lei 13.415.

Isto posto pode-se enveredar pela análise do que propõe a reforma curricular no que diz respeito especificamente à "formação técnica e profissional". Tal redação está presente na proposta desde seu início, ou seja, desde a forma MP 746, e soa estranha, pois parece distinguir a formação técnica da formação profissional, como se não fossem, ambas, educação profissional. Pode-se levantar a hipótese de que tal redação deva-se a um descuido do legislador, o que parece pouco provável.

No entanto, de acordo com Simões (2016), em seus comentários sobre a MP e sobre as alterações nela introduzidas pela comissão mista do Congresso Nacional, "não fica claro como combinar, sem contradições, a opção da profissionalização dentro da carga horária do ensino médio com a legislação vigente na educação profissional", tendo em vista "os formatos desta, propostos na LDB [cf. Lei n. 11.741/2008, não revogados pela Lei 13.415], bem como a legislação 
sobre a carga horária a respeito." De fato, a legislação atual prevê diferentes formatos para a Educação Profissional Técnica de Nível Médio, a qual deveria ocorrer durante todo o período de duração deste e, de forma separada, no âmbito da Educação Básica, a Educação Profissional Inicial (cursos FIC).

Por outro lado, Castioni, durante manifestação em audiência pública realizada em 22 de novembro de 20161, tendo em vista a versão então promulgada da MP 746, levanta a questão de que esta (e também a Lei 13.415/2017, pois o constante da MP se manteve na Lei no que diz respeito à certificação), abriu "algumas possibilidades de os sistemas virem a reconhecer os certificados ou ações realizadas no âmbito das empresas" que digam respeito à formação inicial e continuada. Esta ponderação permite levantar uma hipótese diversa da anterior: a de que talvez a expressão "profissional", na separação entre formação técnica e formação profissional esteja se referindo precisamente a formação inicial e continuada, como se já não houvesse, na LDB, uma clara definição e distinção entre esta, a formação técnica de nível médio e a tecnológica. Assim, a formulação utilizada pela Lei 13.415 mais confunde do que esclarece.

A certificação acima referida é tratada tanto no inciso II do §6ㅇ quanto no §8을 do artigo 4․ 0 inciso do §60 refere-se às certificações intermediárias de qualificação para o trabalho, no caso da formação organizada em etapas de terminalidade. 0 §8ㅇ diz respeito às certificações finais da formação oferecida. Em ambos os casos as certificações estariam sob a responsabilidade dos sistemas de ensino estaduais, ofertantes do ensino médio, realizadas pelas escolas destes ou em parcerias com outras instituições.

No entender de Castioni, para que tais sistemas possam adotar esse procedimento, haverá necessidade de "um ordenamento no âmbito da estrutura da educação profissional" a fim de evitar o problema de que tais sistemas possam estar "regulando coisas muito semelhantes de forma diferenciada, dada a inexistência "de um sistema nacional de certificação profissional". Todavia, parece haver um equivoco nesta última ponderação, pois a Portaria Interministerial n. 5 de 25/04/2014, envolvendo o Ministério da Educação e o Ministério do Trabalho e publicada no DOU de 02/05/2014, p. 14, estabelece a reorganização da Rede Certific, sob cuja responsabilidade estaria a certificação profissional de cursos de formação inicial e continuada (cursos FIC), além de cursos técnicos e de cursos superiores de tecnologia. Além disso, o MEC produziu, em 2014 o Documento Referência Certific, no qual estão especificadas as modalidades de cursos Pronatec a serem certificados (a - certificação de qualificação profissional, tendo por referência os cursos FIC; b- certificação técnica, correspondente aos cursos técnicos). No entanto, a implementação da Rede sofreu vários percalços conforme ressaltado por Costa e Franzoi (2014), de forma que o problema de tais certificações ainda permanece em aberto.

É necessário abordar ainda outro aspecto referente ao inciso I do §6ㅇ da Lei 13.415. De acordo com o parágrafo:

A critério dos sistemas de ensino, a oferta de formação com ênfase técnica e profissional considerará:

I - a inclusão de vivências práticas de trabalho no setor produtivo ou em ambientes de simulação, estabelecendo parcerias e fazendo uso, quando aplicável, de instrumentos estabelecidos pela legislação sobre aprendizagem profissional.

\footnotetext{
${ }^{1}$ Agradeço a Profa. Dra. Monica Ribeiro da Silva que tendo acompanhado todas as audiências realizadas sobre a discussão da MP 746 e obtido seus registro eletrônicos, possibilitou o acesş̨̧̨े HOLOS, Ano 34, Vol. 04
} 
Segundo Castioni, "a aprendizagem profissional (...) é uma reprodução do chamado modelo dual alemão [que] prevê um componente no âmbito da escola e experimentação prática nas empresas". Sua efetivação implica "um contrato de trabalho por prazo determinado", que no caso brasileiro, em decorrência da Lei de Aprendizagem, "só pode ter 24 meses" de duração. A questão levantada por esse pesquisador é a de que "a aprendizagem não é um ordenamento previsto no Ministério da Educação (...) [mas, sim] no âmbito do Ministério do Trabalho, cuja política (...) é apenas fiscalizatória [e] exclusivamente [dedicada] a [verificar] se a empresa está cumprindo a cota" [de aprendizes a serem atendidos] e não "para verificar se aquele aluno matriculado na educação básica está tendo uma assistência do seu tutor na empresa" a quem cabe, conforme o espírito do modelo dual, estabelecer a relação entre os saberes escolares e a prática do trabalho. De acordo com Castioni, a efetivação da aprendizagem profissional, tal como proposto pelo inciso I do $\S 60$ implicaria a criação de condições para viabilizar a Lei da Aprendizagem, do ponto de vista dos contratos de trabalho e da assistência tutorial interna à empresa, sem o que a iniciativa proposta pela reforma seria "inócua".

Tal observação nos parece estar assentada na constatação de que a ausência ou precariedade de tais condições tem dificultado a aplicação efetiva tanto da Lei da Aprendizagem quanto do estágio, reduzindo-se as atividades de "profissionalização" nas empresas à mera execução das atividades de caráter prático, nem sempre afetas, pelo menos do que se conhece sobre o estágio, à formação pretendida, mesmo que de caráter meramente técnica.

No que respeita à organização curricular proposta na Lei, a formação profissional está na mesma condição dos demais itinerários formativos, ou seja, é parte do processo de formação dos alunos destacado da formação geral, representada pelo conjunto dos componentes curriculares que constituem a BNCC. Nesse sentido, constituída dos componentes que mais estritamente dizem respeito a ela, formação profissional. Ao proceder dessa forma a Lei afina-se, pelo menos em parte, com a dualidade entre formação geral ou propedêutica e formação profissional, cujas raízes como se sabe, são de classe, questão essa já exaustivamente tratada nas produções acadêmicas sobre a história da educação brasileira.

Tal dualidade, como sabido, foi mantida e aprofundada no governo FHC, por meio do Decreto 2208/1997, promovendo a separação entre formação geral e formação profissional, inclusive em redes e escolas distintas, subvertendo a oferta conjunta, ainda que não necessariamente integrada, entre ambas, praticada pelas escolas técnicas estaduais e federais desde a década de 1940 e até mesmo, de forma arrevesada, pelas escolas dos sistemas estaduais por intermédio da Lei 5692/1971.

A proposta de formação profissional construída durante o governo Lula buscou superar tudo o que havia sido produzido antes em matéria de educação profissional, pois não só retomou a oferta conjunta de formação geral e específica existente nas escolas técnicas públicas estaduais e federais como o fez sob perspectivas teórico-epistemológicas e filosóficas que conferiram outro sentido à formação profissional, integrando-a à formação geral, tendo em vista a constituição de sujeitos sociais não apenas em condições de desempenhar tecnicamente uma profissão, mas de 
ter sobre ela, sobre o trabalho e sobre a organização deste sob o capital uma visão de totalidade2.

O que a reforma instituída pela Lei 13.415 fez foi, não apenas subverter completamente a proposta de integração entre o ensino médio (formação propedêutica) e formação profissional como, além disso, piorar o quadro oferecido pelo Decreto 2208/1997. De acordo com tal decreto, os jovens matriculados em escolas de ensino médio poderiam, a partir da segunda série, matricular-se, se assim o desejassem, em cursos de formação profissional, oferecidos por diferentes instituições, inclusive privadas, constituindo a forma concomitante. Mas o fariam, continuando a frequentar o ensino médio até o completar por inteiro, o que não é contemplado pela Lei 13.415, posto que a formação profissional é, apenas, um dos itinerários formativos, ficando a formação geral restrita ao início do curso, por meio da BNCC. Além disso, em nenhum dos dois casos propõe-se a integração interna entre seus componentes.

Nesse sentido, a Lei 13.415, além de confusa, contribui também para o aligeiramento da educação profissional a ser disponibilizada pelo ensino médio, o qual é anunciado, em primeiro lugar, pela redução da carga horária desta, na condição de itinerário formativo e, posteriormente, conforme estatuído pelo $\$ 11^{\circ}$ do artigo 4으, pela oferta e reconhecimento de formação profissional realizada por meio de "convênios com instituições de educação a distância com notório reconhecimento", comprovada, tal formação, por atividades de caráter prático não escolar (incisos I, II, III), bem como por cursos oferecidos por centros ou programas ocupacionais (inciso IV), por estudos realizados em instituições de ensino nacionais ou estrangeiras (inciso V) e por cursos presenciais ou a distância (inciso VI).

A insistência com que a Lei 13.415 remete a formação técnica e profissional a instituições parceiras (que podem ser públicas ou privadas) é indicativa, a nosso ver, do reconhecimento, pelo legislador, dos limites com que os sistemas estaduais se defrontam para oferecer formação profissional nas escolas de ensino médio, dada a inexistência, nelas, de condições objetivas para fazê-lo, seja em termos de instalações, equipamentos e mesmo professores habilitados nas diferentes especialidades técnicas, correndo-se o risco, portanto, de repetição do fracasso da formação profissional compulsória imposta ao, então, 2ำ grau, pela Lei 5692/1971.

De outro lado, revela o descompromisso das instituições públicas com a formação profissional dos jovens que frequentarão o ensino médio, além do compromisso com as instituições privadas que o fazem, não apenas onerando o Estado, mas, e este é um aspecto tão importante quanto ao anterior, promovendo tal formação de acordo com os interesses empresariais e não com a visão mais ampla, crítica e autônoma a respeito do trabalho e seu exercício numa sociedade como a brasileira.

No entanto, como a Lei 13.415 é ambígua, permitindo diferentes interpretações a respeito do que pretende, é necessário prestar atenção, além do já tratado, a parágrafos de dois dos artigos que a compõem, nomeadamente, o §3으 do artigo 4ㅇ e o §7으 do artigo 3으 relativamente, o primeiro, à possibilidade de integração, a critério dos sistemas de ensino, entre componentes da BNCC e dos itinerários formativos, e o segundo, à formação integral.

0 §3으 do artigo 4일 diz, textualmente:

\footnotetext{
${ }^{2}$ Ver, a respeito, Frigotto, Ciavatta e Ramos (2005)
} 
A critério dos sistemas de ensino, poderá ser composto itinerário formativo integrado, que se traduz na composição de componentes curriculares da Base Nacional Comum Curricular - BNCC e dos itinerários formativos, considerando os incisos I a V do caput [do artigo 4 ? ].

Tal parágrafo pode ser interpretado como uma abertura para a manutenção da forma integrada de educação técnica de nível médio, como consta da LDB na sua redação atual, na medida em que contempla todos os itinerários formativos. Seria, nessa perspectiva, uma alternativa a explorar. No entanto, é necessário considerar dois aspectos tendo em vista o espírito da Lei, tal como evidenciado nos demais artigos e parágrafos. O primeiro aspecto diz respeito à restrição, implícita na redação, quanto à efetivação do que estatui, uma vez que ela não indica obrigatoriedade dos sistemas de ensino em adotar o disposto no parágrafo, mas apenas a possibilidade de fazê-lo. Como se sabe, os movimentos que os sistemas de ensino possam realizar no sentido de adotar o proposto pela legislação dependem da consideração e aprovação dos Conselhos de Educação estaduais, os quais poderão interpretar de diferentes maneiras a conveniência ou não da adoção do proposto no parágrafo em questão. O segundo aspecto refere-se à interpretação do que pode ser entendido pelos termos "integração" e "integral", que aparecem em alguns parágrafos e artigos da Lei 13.415. Dado o desgaste de tais termos, pelo uso indiscriminado, é possível encontrar diferentes interpretações a respeito.

Na perspectiva da atual redação da LDB, a forma integrada refere-se àquela constante do Decreto 5154/2004, que the deu origem, o que restabeleceria a possibilidade da formação unitária e politécnica. Cabe ressaltar que embora o referido decreto tenha enfatizado a integração entre a formação de caráter geral (atribuição precípua do ensino médio) e a formação profissional técnica do mesmo nível, em contraposição à separação entre elas promovida pelo Decreto 2208/1997, a formação unitária não deve ser entendida tão somente nessa perspectiva, conforme assinalado por Frigotto, Ciavatta e Ramos (2005). Em outros termos, a perspectiva da formação unitária tendo por base a concepção ontológica do trabalho e este como princípio educativo pode e deve ser posta em prática mesmo que a escola ofereça apenas o ensino médio regular.

Essa interpretação, embora possível e desejável, não se coaduna, entretanto, com o espírito da Lei 13.415 (o que é evidenciado pela proposição de itinerários formativos) e, por isso, não me parece que tenderá a vingar nos sistemas de ensino. Pelo contrário, interpretações mais afinadas com as intenções da lei poderão surgir. Uma delas é a que considera a forma concomitante, presente na LDB, como integração entre o ensino médio e a educação profissional técnica. Tal possibilidade não se configura apenas como hipótese, mas tem lastro em parecer do Conselho Nacional de Educação a respeito do Programa VENCE/REDE de educação profissional técnica desenvolvido pela Secretaria de Educação do Estado de São Paulo, em que o aluno cursa o ensino médio em escolas da rede estadual e o ensino técnico nas escolas do Centro Paula Souza, da Secretaria de Ciência e Tecnologia de São Paulo (SEE, 2015, 2017), mas, que, no entanto, é considerada integrada. Nada impede que tal processo se repita por meio de parcerias entre o governo do estado de São Paulo, assim como de outros estados, e instituições privadas 
que oferecem, no estado, educação profissional técnica em moldes que se assemelham ao Programa VENCE/REDE.

Da mesma forma, cabe considerar o disposto no §70 do artigo 3 da Lei 13.415, pois nele se manifesta, novamente, a intenção de oferta de ensino médio que se volta para a formação integral do aluno que o frequenta. A integralidade é compreendida, dessa perspectiva, como a formação relativa a diferentes aspectos da individualidade das juventudes atendidas. Embora esta seja uma interpretação corrente e, de certa forma, adequada, é necessário ponderar que nem sempre a atenção aos vários aspectos da individualidade significa que esta promova a formação integral, que ocorrerá apenas se não forem percebidos e tratados como dimensões que se somam, ou que se justapõem, mas como totalidade. Em São Paulo, assim como em outros estados da federação multiplicam-se, por essa razão, as denominadas Escolas de Tempo Integral, cuja denominação, por si só, produz, muitas vezes, a visão distorcida de que a formação integral somente é possível em escolas dessa natureza ou, ao contrário, que a ampliação do tempo diário de trabalho escolar implica, necessariamente, formação integral.

É necessária, portanto, uma incursão mais detida sobre as características de tais escolas, seja porque esta é uma dimensão privilegiada pela Lei 13.415 , seja porque, o modelo proposto pela Secretaria de Educação de São Paulo guarda, de alguma forma, relações com a proposta do itinerário denominado "formação técnica e profissional", embora não se volte especificamente para este. Referido modelo espelha-se na Escola de Tempo Integral de Pernambuco, idealizada por uma entidade privada, o Instituto de Co-Responsabilidade pela Educação (ICE), que se propagou por vários estados brasileiros, propondo-se implantar sua filosofia educacional em escolas de nível médio públicas, tendo por base um modelo de gestão e um modelo pedagógico. Em São Paulo o programa tem o apoio de instituições privadas (cf. Adrião e Garcia, 2014), várias das quais, como o Instituto Natura, a Fundação Vitor Civita, a Fundação Lemann, o Instituto Unibanco, a Fundação Itaú Social e a Fundação Bradesco são entusiastas da atual Base Nacional Comum Curricular3. O modelo de gestão, que lembra manuais de organização empresarial e de RH de empresas, tendo por base autores dessas áreas, acaba por constituir, pela prática e repetição contínua, uma estratégia de formação de valores, sem parecer isso aos participantes.

O modelo pedagógico está baseado no Relatório Delors (1998), tendo em vista os denominados quatro pilares da educação: aprender a conhecer, aprender a fazer, aprender a viver juntos, aprender a ser, em textos de Costa (1997 e 2014), na Constituição Federal, na LDB 9394/96 e nas Diretrizes Curriculares Nacionais para o Ensino Médio, de 1998. Tal modelo é marcado pelo enfoque da formação por competências. Os elementos centrais organizadores do currículo são: o Projeto de Vida do aluno (mencionado no $§ 70$ do Art. 3ㅇ) e o protagonismo juvenil. Ao redor desses elementos giram as atividades de aprendizagem da parte diversificada da matriz curricular, além de atividades complementares (robótica, informática, empreendedorismo, línguas, etc., orientação de estudo, preparação acadêmica e "mundo do trabalho").

Em suas considerações a respeito das escolas públicas de tempo integral, Cavalieri (2014, p. 1214) chama a atenção para um aspecto que as pesquisas a respeito dessas escolas têm

\footnotetext{
${ }^{3}$ A respeito das relações entre a Lei 13.415/2016 e a Base Nacional Comum Curricular veja-se Ferretti e Silva (2017).
} 
apontado, ou seja, a "justaposição à rotina escolar de atividades complementares, chamadas de 'atividades de educação integral'”, como as apontadas no programa da Secretaria de Educação de São Paulo. Fazendo a crítica a tal concepção, a autora comenta que "referir-se a 'atividades de educação integral' é considerar que há atividades especializadas que, em si mesmas, promovem educação integral", subvertendo, com isso, o sentido complexo do conceito que diz respeito à consideração do "indivíduo como ser complexo e indivisível, [que] no âmbito escolar se expressa por meio de um currículo, também integrado e [que] se empenha na formação integral do indivíduo em seus aspectos cognitivos, culturais, éticos, estéticos e políticos" (idem).

Dois outros aspectos abordados pela Lei 13.415, referem-se diretamente à "formação técnica e profissional". O primeiro diz respeito às modificações introduzidas, por meio do artigo 6으, que diz respeito aos docentes que poderão atuar nas escolas tendo em vista a formação acima referida, bem como do artigo 7으, que trata da formação dos docentes para atuar na educação básica. O artigo 60 modifica o artigo 61 da LDB 9394/96 para admitir como docentes, exclusivamente do itinerário "formação técnica e profissional", "profissionais com notório saber reconhecido pelos respectivos sistemas de ensino, para ministrar conteúdos afins à sua formação ou experiências profissionais, atestados por titulação específica ou prática de ensino em unidades educacionais da rede pública ou privada ou das corporações privadas em que tenham atuado".

A proposição não inova em relação a um aspecto que vem sendo observado historicamente na educação profissional desenvolvida no país. Praticamente a totalidade dos professores dos cursos profissionais técnicos que oferecem formação específica é originária, como graduados, mestres ou doutores das áreas em que em que se titularam, parte dos quais detentores, também, de certificados de cursos de licenciatura nas respectivas áreas. A novidade consiste na sua admissão pelo "notório saber", cuja definição não é simples e cuja "certificação" é ainda mais complexa, pois variará conforme o sistema de ensino, as unidades educacionais onde o postulante lecionou e as corporações em que atuou, estabelecendo-se, por essa forma, avaliações que terão como base pelo menos duas referências muito diversas, quais sejam, o exercício do magistério e o desempenho na empresa.

Cabe notar que o artigo não faz qualquer menção específica à licenciatura como critério para a certificação de "notório saber". O único critério que inspira mais confiança é a titulação, ainda que a qualidade desta possa variar de instituição para instituição. O não estabelecimento de critérios para a definição do processo de avaliação do notório saber e dos avaliadores que o executarão, ou a definição fraca destes, poderá implicar a certificação precária e, com isso, comprometer o desempenho do docente cuja "notoriedade" será atestada. Os desdobramentos técnico-burocráticos que isso implica não são simples. A questão mais séria é a possibilidade de que, por essa forma, as admissões se façam não mais por concursos públicos, que é a forma mais efetiva de avaliar o saber específico detido pelo candidato, mas por indicações que podem obedecer a critérios não afinados com a docência na formação profissional.

Todavia, ainda que as situações pregressas possam ser resolvidas satisfatoriamente, resta o problema principal que tem sido objeto de polêmicas históricas na educação profissional, bem como de busca de soluções. Trata-se de que, apesar de deter saberes sobre sua área de 
formação, o profissional que atua não apenas na educação profissional, mas em toda a educação básica necessita ser formado como professor, ou seja, deter um saber específico sobre educação, tanto do ponto de vista teórico-filosófico quanto prático. Ser um bom engenheiro, administrador ou matemático, por exemplo, não faz desses profissionais, necessariamente, bons educadores. Esse fato, reconhecido no âmbito da educação profissional, levou à proposição de cursos de licenciatura ou de complementação pedagógica. Até mesmo a desastrada formação profissional compulsória instituída pela Lei 5692/1971, o reconheceu, o que levou à proposta dos Cursos de Esquema I e Esquema II. Os cursos de licenciatura são uma exigência para os profissionais que lecionam as várias disciplinas da educação básica. Porque não o seriam para os que atuam especificamente na educação profissional? Assim, retorna-se à questão inicial: de qual "notório saber" deve ser portador o postulante à condição de professor no itinerário de formação técnica e profissional? E quem o atestará, sem sombra de dúvidas?

Por outro lado, o artigo 7ำ, que diz respeito à formação de docentes para atuar na educação básica introduz modificação no artigo 62 da LDB 9394/96, evidenciando a inconsistência da Lei 13.415 a respeito, pois aí se diz que a formação do docente para atuar nesse nível da educação brasileira, "far-se-á em nível superior, em curso de licenciatura plena". Mas, se a educação profissional, ou, para usar os termos da lei, a "formação técnica e profissional", faz parte da educação básica, ou pelo menos da etapa do ensino médio porque o artigo 6 não explicita essa exigência como parte do notório saber?

Deve-se considerar, ainda, a modificação que o artigo 9으 da Lei 13.451 introduz no artigo 10 da Lei 11.494/2007, a qual diz respeito ao financiamento do ensino brasileiro e, particularmente, do ensino médio, por intermédio do FUNDEB. De acordo com a modificação proposta, acresce-se ao conjunto de "etapas, modalidades e tipos de estabelecimento de ensino da educação básica", contemplados pelo FUNDEB, o inciso XVIII que se refere à "formação técnica e profissional". Todavia, o inciso XIII da Lei 11.494 já contempla o "ensino médio integrado à educação profissional". Não haveria aí uma duplicação das destinações dos recursos do FUNDEB à educação profissional técnica, ou, talvez uma disputa por tais recursos entre o ensino médio integrado à educação profissional e a "formação técnica e profissional" proposta pela Lei 13.451? Ou seria o FUNDEB utilizado para a cobertura de custos oriundos da atribuição da formação técnica e profissional a instituições privadas, contrariando os objetivos de tal fundo?

Finalmente, é necessário trazer ao debate a situação dos Institutos Federais de Educação, Ciência e Tecnologia frente ao estatuído pela Lei 13,415. Como é sabido, a tais instituições foi atribuída, desde sua criação, a responsabilidade maior, ainda que não exclusiva, pela implementação da proposta do Ensino Médio integrado à Educação Profissional Técnica de nível médio, tendo em vista o histórico das antigas escolas técnicas e dos CEFETs de que se originaram. Todavia, como também sabido, os sistemas estaduais de educação responsáveis pelo desenvolvimento do Ensino Médio não teriam condição estrutural e de pessoal para assumir tal responsabilidade, exceção feita aos casos de São Paulo e do Rio de Janeiro que possuem uma rede estadual de escolas técnicas vinculadas, em cada estado, à sua respectiva Secretaria de Ciência e Tecnologia, mas que não se dispuseram a tal nos anos que se seguiram à proposta de formação integrada. Seriam os IFs colocados na situação de fazer a oferta de Educação 
Profissional, como previsto na Lei 3.415 , mas na forma restrita e fundamentalmente instrumental como previsto na legislação?

Os Institutos Federais, por seu turno, fazem parte da rede federal de ensino, além de contarem, por sua própria definição institucional, com autonomia administrativa e pedagógica. 0 Conselho Nacional dos Institutos Federais (CONIF) manifestou-se, em diversas ocasiões, não apenas contra o proposto pelo Projeto de Lei 6840/2013, como também contra a MP 746.

Mas, como instituições de ensino os IFS devem, por outro lado, observar o prescrito pela LDB 9394/1196, modificada, inclusive no que toca à formação profissional, pela Lei 13.415/2017, levando em conta, conforme a análise realizada neste texto, que o §3으 do artigo 4을 descortina, ainda que de forma limitada, conforme a interpretação que lhe for dada, a possibilidade de continuidade do projeto de Ensino Médio Integrado à Educação Profissional. Todavia, não é possível ignorar, conforme pesquisas realizadas em nível de mestrado e doutorado, que mesmo antes da existência da Lei $13.415 / 2017$, os IFs vinham encontrando dificuldades para promover a integração pretendida tendo por referência sua fundamentação teórico-epistemológica e filosófica.

Os elementos constitutivos da visão da Lei 13.415 a respeito da Educação Profissional Técnica de nível médio abrem espaço para uma série de questionamentos. Como é possível perceber, as proposições constantes da referida Lei a respeito da formação profissional técnica de nível médio, a par do aligeiramento desta e de seu caráter manifestamente pragmático, centrado apenas na formação técnica de mão de obra, descura da constituição omnilateral do ser humano. Além disso, a meu ver, descura até mesmo dos interesses das empresas se se der crédito à sua demanda por trabalhadores melhor preparados em termos de formação geral e profissional, dado que a proposta pela reforma é, no meu entender, de pior qualidade daquela que vem sendo oferecida no país. Por outro lado, pode, contraditoriamente, estar atendendo tais interesses se eles se voltam apenas para a formação de ocupantes de postos de menor expressão, compondo o mercado secundário de trabalho interno à empresa, de quem se exige menos em termos de qualificação, pagando-lhes, em contrapartida, menores salários, com menores garantias trabalhistas.

Cabe prestar atenção, conforme apontado no início deste artigo, aos processos de regulamentação e implementação do proposto e, mais que isso, atuar no sentido de minorar os efeitos negativos que a Lei 13.415 tem condição de produzir tanto no ensino médio quanto na educação profissional. A respeito, atente-se para as consequências danosas que representarão para o país, manietado por um congelamento de gastos por 20 anos que prejudica principalmente os setores de baixa renda e por uma reforma trabalhista que promove o desemprego, os empréstimos no valor de 250 milhões de dólares que, em julho de 2007, o governo autorizou o MEC a contratar com o Banco Internacional para Reconstrução e Desenvolvimento (BIRD) para financiar parte da implementação da reforma do ensino médio pelos vários entes estaduais. 


\section{REFERÊNCIAS}

ADRIÃO, Theresa; GARCIA, Teise. Subsídio público ao setor privado: reflexões sobre a gestão da escola pública no Brasil. Políticas Educativas, Porto Alegre, v. 7, n. 2, p. 110-122, 2014

BRASIL/DOU. Lei 13.415 de 16 de fevereiro de 2007. Brasília, Primeira Parte, p. 1-3, 2017.

BRASIL/Presidência da República. Lei 11.494 de 20 de junho de 2007. Brasília, 2007.

BRASIL/MEC. Portaria Interministerial n. 5 de 25/04/2014. DOU de 02/05/2014 (no 82, Seção 1, pág. 14), Brasília, 2014.

BRASIL/MEC. PDE/PRONATEC. Documento Referência Pronatec Certific, Brasília, 2014.

CASTIONI, Remi. Manifestações na audiência pública na Câmara Federal sobre a MP 746 em 22/11/2016, não publicado.

CAVALIERI, Ana Maria. Escola pública de tempo integral no Brasil: filantropia ou política de estado? Campinas: Educação \& Sociedade, v. 35, n. 129, p. 1205-1222, out.-dez. 2014.

COSTA, Antonio Carlos Gomes da. Pedagogia da presença: da solidão ao encontro. Belo Horizonte: Modus Faciendi, 1997. 140

Educaçãolnterdimensional.http://associacaopelafamilia.org.br/aspf/cat/POR\%20UMA\%2 OEDUCA\%C7\%C3O\%20 INTERDIMENSIONAL\%20II.pdf, acesso em 25/08/2014.

COSTA, Rita de Cássia Dias; FRANZOI, Naira Lisboa. Politicas públicas de reconhecimento de saberes no Brasil e em Portugal: aproximações e especificidades. X Anped Sul, Florianópolis, outubro, 2014.

FERRETTI, Celso João; SILVA, Monica Ribeiro da. A reforma do Ensino Médio no contexto da Medida Provisória n. 746/2016: Estado, currículo e disputas por hegemonia. Educação \&Sociedade, Campinas, v. 38, n. 139, p. 385-404, abr.-jun. 2017.

FRIGOTTO, Gaudêncio; CIAVATTA, Maria; RAMOS, Marise (orgs.). Ensino Médio Integrado: concepções e contradições. São Paulo: Cortez, 2005.

MEC/UNESCO. Educação, um tesouro a descobrir. São Paulo: Cortez, 1998.

SIMÕES, Carlos Artexes. Vozes dissonantes na reforma do ensino médio, 2016, não publicado.

SÃO PAULO/SECRETARIA ESTADUAL DE EDUCAÇÃO. Resolução SE no 8, de 12-3-2015.

SÃO PAULO/SECRETARIA ESTADUAL DE EDUCAÇÃO. Resolução SE-1, de 6-1-2017. 